\title{
Publication rates of abstracts presented at the annual congress of the Turkish Society of Colorectal Surgery (years 2003-2011)
}

Ulvi Mehmet Meral', Murat Urkan², Ümit Alakuș², Emin Lapsekili², Nidal iflazoğlử, Aytekin Ünlü², Pelin Özmen ${ }^{4}$, Sezai Demirbaș

\section{ABSTRACT}

\section{Cite this paper as:} Meral UM, Urkan M, Alakus Ü, Lapsekili E, íflazoğlu N, Ünlü A, Özmen P, Demirbaş $S$. Publication rates of abstracts presented at the annual congress of the Turkish Society of Colorectal Surgery (years 2003-2011). Turk J Surg 2017; 33(2): $87-90$

'Department of General Surgery, İzmir Military Hospital, İzmir, Turkey

${ }^{2}$ Department of General Surgery, Gülhane Training and Research Hospital, Ankara, Turkey ${ }^{3}$ Department of Gastroenterological Surgery, Çukurova University School of Medicine, Adana, Turkey ${ }^{4}$ Department of Military Health Services, Gülhane Training and Research Hospital, Ankara, Turkey

This study was presented at the $20^{\text {th }}$ Turkish Surgical Society National Congress, 13-17 April 2016, Antalya, Turkey.

\section{Address for Correspondence} Ulvi Mehmet Meral e-mail: ulvimeral@yahoo.com

Received: 07.11.2015 Accepted: 25.12.2015

\section{(c) Copyright 2017} by Turkish Surgical Association

Available online at www.turkjsurg.com
Objective: The aim of our study is to examine the Publication Rate of Congress of Turkish Society of Colorectal Surgery meeting abstracts and determine the factors affecting publication rate.

Material and Methods: All presentations at Congress of Turkish Society of Colorectal Surgery congresses held in 2003, 2007, 2009, 2011 were retrospectively assessed. Manuscripts indexed in Google-Scholar database were included. The meeting year, study type, presentation type, title and time to publication of studies were assessed. Actual impact factor values were assessed to introduce the scientific power of the journals.

Results: Among a total of 614 abstracts presented at these congresses, 139 (22.6\%) presentations were published in various medical journals. The publication rate was higher in oral presentations as group compared to poster presentations $(29.7 \%$ vs. $19.5 \%)(p<0.001)$. Mean time to publication period was $20.4( \pm 21.1)$ months. $78(56.1 \%)$ of published articles were published in SCI-E journals while 61 (43.9\%) were published in non-SCI-E journals. Experimental studies had a higher Publication Rate in analysis of publication rate according to study type $(\mathrm{p}<0.001)$. Prospective clinical studies had a higher publication rate than retrospective studies. The journals in which oral presentations had been published had greater impact factor than journals in which poster presentations had been published $(p=0.02$ ). If published; prospective clinical studies were published in journals with greater impact factor than retrospective studies $(p=0.04)$.

Conclusion: The quality of a meeting is correlated with the publication of abstracts accepted as presentations. Congress of Turkish Society of Colorectal Surgery congress is an efficient meeting for researchers, and have a lower PR as compared to international congresses while having a similar publication rate to equivalent scientific meetings. Being more selective during abstract acceptance should increase the Publication Rate and quality of Congress of Turkish Society of Colorectal Surgery congresses.

Keywords: Abstract, annual congress, Turkish Society of Colorectal Surgery, publication rate

\section{INTRODUCTION}

A scientific congress is an environment in which physicians with the same specialty and other health staff participate in, the results of which is shared as abstracts, and in which ideas are exchanged with one another. The abstracts presented in scientific congresses (oral/poster) are evaluated by the commissions that are assigned by the congress scientific committee during the preparation period of the congress and it is decided if the studies will be accepted in the congress or not.

The publication of abstracts in national/international peer-reviewed journals after the congress is one of the indicators of the scientific value of the congress. In a Cochrane meta-analysis published in 2007, it was stated that the publication rate of the abstracts presented in a congress was $44.5 \%$ (1). Articles evaluating the conversion rate of the abstracts presented in international congresses into publications are limited. Similarly, the number of studies that are conducted in order to reveal the scientific efficiency of national congresses held in our country is also low. In these studies, it is reported that the conversion rate of the abstracts presented in the congresses to publications is very limited (between $5.7 \%$ and $28.6 \%$ ) (2-7).

Turkish Society of Colorectal Surgery (TSCRS) organizes periodic scientific activities in order to develop the professional, scientific and social relationships between its members in accordance with its aims. The congresses of TSCRS, which are organized once in two years, are one of the important scientific activities. In our study, we aimed to define the conversion rate of the abstracts presented in the congresses organized in 2003, 2007, 2009 and 2011 to articles in peer-reviewed journals, to determine the factors (presentation type, study type, congress year etc.) effecting publication rate.

\section{MATERIAL AND METHODS}

The abstracts of oral presentations (OP) and poster presentations (PP) presented at the TSCRS congresses in 2003, 2007, 2009 and 2011 were extracted from the congress database. Since the congress in 2005 
was organized in association with the International Society of University Colon and Rectal Surgeons - ISUCRS congress in 2006, abstracts of that congress were not included in the study. A database including certain characteristics of the abstracts such as presentation type (oral/poster), title, study type (clinic study, experimental study, case presentation, review) (prospective/retrospective) was established, and all abstracts that were included in the study were entered into this database individually. Abstracts were classified under ten different categories according to their subjects, and they were analyzed. Abstracts were then searched in Google Scholar (http:// scholar.google.com.tr) database. The last date of this search was July $15^{\text {th }} 2015$. The first author's name and a key word in the abstract's title were used for searching. If the article could not be found then all authors' names were searched individually. Since both English and Turkish articles were searched in the database concurrently, entire key words were used in both English and Turkish. Even if there was a change in the number and sequence of the authors of the article, it was considered as having been published provided that there was no change in the hypothesis and sample of the study. In addition, provided that there was no change in the method and results of the study, the increase in the sample size was also considered as being published since it is assumed that a preliminary presentation had been done in the congress. The articles, the journal on which it was published in, date of publication, quality of the journals (Science Citation Index-Expanded (SCI-E)/out of SCI-E) were noted. The examination of each journal about their $\mathrm{SCl}$ E status and their current impact factor (IF) were realized via www.researchgate.com (8). The duration between the date of the congress and publication date of the article was noted in months. The abstracts which have been published prior to the congress were also included in the study.

In a study evaluating the interval between presentation of an abstract in a congress and its publication in a peer-reviewed journal as an article, it was reported that $90 \%$ of the abstracts that have been published as articles were published within four years (9). Therefore, since we conducted our study in 2015, the TSCRS congress in 2011 was selected as the most current meeting. Since our study is a retrospective archive work, the approval of the ethics committee did not required. Also we did not use patient data in our study. The study did not require informed consent.

\section{Statistical Analysis}

After the database was entered into a computer, Statistical Package for the Social Sciences version 20.0 (IBM Corp.; Armonk, NY, USA) was used for statistical analysis. Numerical data were evaluated with independent sample T-test and One-Way ANOVA test, and categorical data were evaluated with Pearson chi-square test and Fishers-Exact test. Numeric variables were presented as average and standard deviation, and categorical variables were presented as percentages. The results were assessed in 95\% confidence interval and the results with $<0.05 p$ value were considered as significant.

\section{RESULTS}

Six hundred and fourteen abstracts were presented in 4 congresses that had been organized between 2003 and 2011. Two hundred and nine (34\%) of these abstracts were OPs whereas
Table 1. Classification of the abstracts presented at congresses according to study type

\begin{tabular}{|lcccc|}
\hline Type of study & Total & Publication $(+)$ & $\%$ & $\mathbf{p}$ \\
\hline Clinical study & 419 & 91 & 21.7 & $<0.001$ \\
\hline Experimental study & 33 & 19 & 57.6 & \\
\hline Case presentation & 159 & 29 & 18.2 & \\
\hline Review & 3 & 0 & 0 & \\
\hline Total & 614 & 139 & 22.6 & \\
\hline
\end{tabular}

Table 2. Average time until publication of the abstracts according to years

\begin{tabular}{|c|c|c|c|c|c|c|}
\hline $\begin{array}{l}\text { Year of } \\
\text { congress }\end{array}$ & $\mathrm{n}$ & $\begin{array}{l}\text { Average } \\
\text { time until } \\
\text { publication } \\
\text { (months) }\end{array}$ & SD & Minimum & Maximum & $p$ \\
\hline 2003 & 13 & 40.6 & 26.04 & 2 & 92 & \\
\hline 2007 & 23 & 20.7 & 23.13 & 2 & 80 & 0.003 \\
\hline 2009 & 45 & 18.3 & 22.41 & -25 & 71 & \\
\hline 2011 & 58 & 17.3 & 15.20 & -33 & 50 & \\
\hline Total & 139 & 20.4 & 21.06 & -33 & 92 & \\
\hline
\end{tabular}

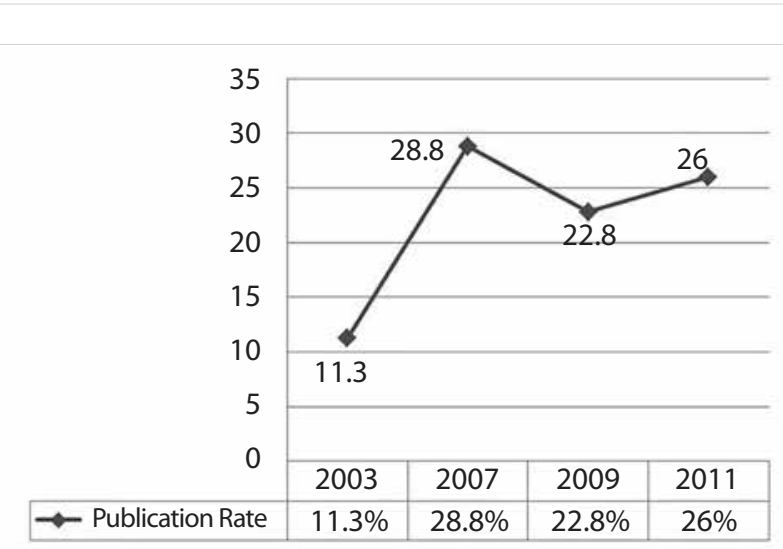

Figure 1. Publication rates of the abstracts according to years

tics; 419 (68.2\%) abstracts were clinic studies, 33 (5.4\%) were experimental studies, 159 (25.9\%) were case presentations, and $3(0.5 \%)$ were reviews (Table 1$)$. Ninety-seven $(23.2 \%)$ of the clinical studies were prospective studies whereas 322 $(79.6 \%)$ were retrospective in nature.

One hundred and thirty-nine (22.6\%) of 614 abstracts presented in the congresses were published as articles in 49 different journals that were listed by Google Scholar (http://scholar. google.com.tr) database. The distribution of publication rate according to years was found as: $13 / 115(11.3 \%)$ in 2003 , $23 / 80(28.8 \%)$ in $2007,45 / 197(22.8 \%)$ in 2009 , and $58 / 223$ (26\%) in 2011 (Figure 1). While the publication rate of OPs was $28.7 \%$, it was $19.5 \%$ for PPs $(p=0.001)$.

The duration between the date of congress and the publication date of abstract as an article was compared according to years. While the publication duration of the abstracts was 20.4 month, this duration was 40.6, 20.7, 18.3 and 17.3 months for 
Table 3. Classification of the published abstracts according to their subjects

\begin{tabular}{|lcccc|}
\hline Title & Publication (+) & Total & $\%$ & $\mathbf{p}$ \\
\hline Appendix diseases & 11 & 53 & 20.8 & 0.62 \\
\hline Hemorrhoidal disease & 5 & 25 & 20 & \\
\hline $\begin{array}{l}\text { Intraabdominal non-colorectal } \\
\text { diseases }\end{array}$ & 14 & 41 & 34.1 & \\
\hline Colonoscopy & 3 & 17 & 17.6 & \\
\hline Colorectal tumors & 35 & 160 & 21.9 & \\
\hline Laparoscopic colorectal surgery & 7 & 24 & 29.2 & \\
\hline Perianal diseases & 9 & 61 & 14.8 & \\
\hline Pilonidal disease & 11 & 43 & 25.6 & \\
\hline Stomas & 8 & 28 & 28.6 & \\
\hline Non-oncologic colorectal Diseases & 36 & 162 & 22.2 & \\
\hline Total & 139 & 614 & 22.6 & \\
\hline & & &
\end{tabular}

Table 4. The first 20 journals in which abstracts were published as articles (According to frequency)

\begin{tabular}{|c|c|c|c|c|}
\hline & $\begin{array}{l}\text { Name of } \\
\text { Journal }\end{array}$ & $\begin{array}{l}\text { Number of } \\
\text { abstracts } \\
\text { published }\end{array}$ & $\%$ & $\begin{array}{l}\mathrm{SCl} / \\
\mathrm{SCl}-\mathrm{E}\end{array}$ \\
\hline 1 & Turkish Journal of Surgery & 16 & 11.5 & - \\
\hline 2 & World Journal of Surgery & 7 & 5 & + \\
\hline 3 & Diseases of Colon and Rectum & 5 & 3.6 & + \\
\hline 4 & $\begin{array}{l}\text { Journal of Diseases of the } \\
\text { Colon and Rectum }\end{array}$ & 5 & 3.6 & - \\
\hline 5 & Ulusal Travma ve Acil Cerrahi Dergisi & 4 & 2.8 & + \\
\hline 6 & Gulhane Medical Journal & 3 & 2.1 & - \\
\hline 7 & Indian Journal of Surgery & 3 & 2.1 & + \\
\hline 8 & $\begin{array}{l}\text { Int. Journal of Clinical and } \\
\text { Experimental Medicine }\end{array}$ & 3 & 2.1 & + \\
\hline 9 & $\begin{array}{l}\text { Journal of Laparoendoscopic \& } \\
\text { Advanced Surgical Techniques }\end{array}$ & 3 & 2.1 & + \\
\hline 10 & The American Journal of Surgery & 3 & 2.1 & + \\
\hline 11 & The Turkish Journal of Gastroenterology & 3 & 2.1 & + \\
\hline 12 & World Journal of Gastroenterology & 3 & 2.1 & + \\
\hline 13 & Saudi Medical Journal & 2 & 1.4 & + \\
\hline 14 & Asian Journal of Surgery & 2 & 1.4 & + \\
\hline 15 & Journal of Gastrointestinal Surgery & 2 & 1.4 & + \\
\hline 16 & Journal of Investigative Surgery & 2 & 1.4 & + \\
\hline 17 & International Journal of Colorectal Disease & se 2 & 1.4 & + \\
\hline 18 & Hepatogastroenterology & 2 & 1.4 & + \\
\hline 19 & The Medical Bulletin of Haseki & 2 & 1.4 & - \\
\hline 20 & Clinics & 2 & 1.4 & + \\
\hline
\end{tabular}

the years of 2003, 2007, 2009 and 2011,respectively (Table 2). OP and PP abstracts were compared according to publication durations, but no significant difference was observed ( $p=0.17$ ). When it was evaluated according to abstract subjects, "Non-
Oncologic Colorectal Diseases" ranked first with 162 abstracts and "Colorectal Tumors" the second with 160 abstracts. When the publication rate was examined according to subjects, "Intraabdominal Non-Colorectal Diseases" had a PR of 34.1\% whereas "Laparoscopic Colorectal Surgery" ranked second with a rate of $29.2 \%$. Analysis of publication rate and publication duration according to subject revealed no significant difference ( $p=0.62, p: 0.73$ respectively) (Table 3 ). While 78 (56.1\%) abstracts that have been published as an article were published in SCl/SCl-E journals, 61 (43.9\%) were published in national/international journals that were not included within the $\mathrm{SCl}-\mathrm{E}$ directory. It was determined that the journals in which the articles were mostly published are Turkish Journal of Surgery, World Journal of Surgery, and Diseases of Colon and Rectum along with Journal of Diseases of the Colon and Rectum (Table 4). When the publication rate was examined according to study type, it was seen that experimental studies had the highest rate of being published $(p<0.001)$. When clinic studies were compared according to their prospective and retrospective nature, prospective clinic studies were converted to published articles more than retrospective studies. ( $38.1 \%$ and $16.8 \%$ respectively) $(p<0,001)$. The abstracts which have been published in $\mathrm{SCl} / \mathrm{SCl}-\mathrm{E}$ listed journals were further examined for IF values of these journals. It was determined that the mean IF of the journals in which OPs have been published were higher than that of the journals in which PPs have been published ( 2.08 and 1.20 , respectively) $(p=0.02)$. It was determined that prospective clinic studies were published in the journals with higher IF values in comparison to retrospective studies ( 2.32 and 1.36 , respectively) $(p=0.04)$. Analysis of IF analysis according to study type $(p=0.16)$ and congress year $(p=0.78)$ revealed no significant difference.

\section{DISCUSSION}

The presentation of a study in national/international congresses enables transfer of newly discovered diagnosis/treatment methods to large scientific populations. On the other hand, the publication of studies in national/international peer-reviewed journals allows transfer of results to the whole scientific population without any limitations (10).

Six hundred and fourteen abstracts were presented in four TSCRS congresses that were included in this study, and 139 $(22.6 \%)$ of these abstracts were published as articles in national/international peer-reviewed journals. In parallel with reports from meetings by similar societies, the quantity of OP abstracts are lower than PP abstracts' in TSCRS congresses. The reported overall publication rates vary from $5.7 \%$ to $58 \%$. Kabay et al. (7) analyzed the publication rates of abstracts that were presented in National Surgery Congress between 1996 and 2004 as articles on peer-reviewed journals, and they stated that $5.7 \%$ of the abstracts have been published in international journals. This rate was determined as $22.6 \%$ in our study. The difference between the two studies was attributed to study methodology; the authors of the mentioned study have only used the PubMed search engine and thus have only included international journals that were indexed in that search engine into their study, while we used the Google Scholar (http://scholar.google.com.tr) database providing a larger search field. Therefore, the disparity does not indicate a quality difference between the two congresses. Yalçınkaya et al. (11) analyzed the abstracts that were presented at the $20^{\text {th }}$ National 
Turkish Orthopedics and Traumatology Congress in 2007, and although that was an international congress, they found the publication rate in international journals indexed in PubMed search engine as $29.5 \%$. This high publication rate in that study was attributed to the fact that 52 of these abstracts were published on Acta Orthopaedica et Traumatologica Turcica, which is an $\mathrm{SCl}$-E indexed Turkish journal. In our study, while $28.7 \%$ of the OP abstracts presented at TSCRS congress were published as articles, this rate was $19.5 \%$ for PP abstracts. Accordingly, the mean IF value of the journals in which OP abstracts have been published were significantly higher than that of the journals in which PP abstracts have been published. As pointed out by similar studies, this result which we have found about TSCRS congress abstracts suggests that; congress assessment commission has classified the abstracts as OP and PP, whereas the studies which are possible to be articles in higher quality journals were determined as OP and those with lower publication value were determined as PP. (4-7). In contrast, another study evaluating publication rate of the abstracts which have been presented at congresses organized by American Orthopedic Surgery Society reported that the publication possibility of the OP abstracts was similar to the publication possibility of the PP abstracts (52\%-47\%) (12).

Our publication analysis of abstracts were ended on August 2015, later analysis for relevant congresses of TSCRS abstracts may include additional data and change the present results. We considered this situation as a limitation against our study.

The publication rate of the abstracts that have been presented at the congresses and published as articles in SCI-E journals were analyzed along with their IF according to their prospective or retrospective study design. In parallel to literature, it was concluded that prospective studies are more important than retrospective studies due to their high publication rates and IF values. Publication of the congress abstracts in peerreviewed journals is one of the pre-requisite conditions of certain scientific societies for "sending an abstract to a congress". However, such a pre-requisite does not exist for TSCRS congresses. In our study, we determined that 10 (7.2\%) of the 139 abstracts were published as articles in /international peer-reviewed journals prior to the congress. It was determined that clinic studies constituted an important percentage of studies that were presented at the Turkish Society of Colorectal Surgery Congress, but that experimental studies have the highest publication rate as an article in peer-reviewed journals.

\section{CONCLUSION}

In conclusion, although the abstracts presented in Turkish Society of Colorectal Surgery Congresses yielded an equivalent publication rate with other similar organizations of similar scientific societies with its rate of $22.6 \%$, this rate was lower in comparison with abstracts presented in international congresses. Being selective in the acceptance of abstracts to be presented at TSCRS congresses, and including the valuable studies into the congress may increase the publication rates of the abstracts.

\section{Ethics Committee Approval: N/A.}

Informed Consent: Not required in this study.

Peer-review: Externally peer-reviewed.

Author Contributions: Concept - U.M.M., A.A., M.U.; Design - N.I., A.U., U.M.M.; Supervision - P.O., U.M.M., S.D.; Resource - U.M.M., N.I.; Materials - E.L., U.M.M.; Data Collection and/or Processing - Ü.A., A.Ü.; Analysis and/or Interpretation - S.D., E.L., P.O.; Literature Search - Ü.A., M.U., A.Ü.; Writing Manuscript - E.L., N.I; Critical Reviews - M.U., P.O., S.D.

Acknowledgements: The authors thank to Aylin Öztürk Meral M.D. for her support to our study.

Conflict of Interest: No conflict of interest was declared by the authors.

Financial Disclosure: The authors declared that this study has received no financial support.

\section{REFERENCES}

1. Scherer RW, Langenberg P, von Elm E. Full publication of results initially presented in abstracts. Cochrane Database of Syst Rev 2007; 18: MR000005. [CrossRef]

2. Ersoy GŞ, Eken M, Öztekin D, Çöğendez E, Eroğlu M. The International publication rates of abstracts presented in The National Gynecology and Obstetrics Meetings in the field of reproductive endocrinology and infertility. Zeynep Kamil Tıp Bülteni 2015; 46: 63-68.

3. Kalyoncu U, Çınar M, Demirağ MD, Yılmaz S, Erdem H, Kiraz S, et al. The assessment of abstracts presented in National Rheumatology Congresses: where do we stand? RAED Dergisi 2011; 3: 6-10.

4. Özyurt S, Kaptanoğlu AF. Publication Rates of Abstracts Presented at The Biannual Turkish National Dermatology Meetings between 2004 and 2008. Dermatoz 2012; 3: 7-11.

5. Seçil M, Uçar G, Şentürk Ç, Karasu Ş, Dicle O. Publication rates of scientific presentations in Turkish national radiology congresses. Diagn Interv Radiol 2005; 11: 69-73.

6. Kaya Mutlu E, Çelik D, Mutlu C, Razak Özdinçler A. Publication rates of oral presentations accepted at Advances in Physiotherapy Symposiums. Turk J Physiother Rehabil 2013; 24: 145-149.

7. Kabay B, Teke Z, Erbiş H, Koçbil G, Tekin K, Erdem E. Publication rates of scientific presentations in Turkish National Surgical congress. Turk J Surg 2005; 21: 130-134.

8. [internet] Research-Gate Academic Search Appliance. Available from: http://www.researchgate.net/

9. Hackett PJ, Guirguis M, Sakai N, Sakai T. Fate of abstracts presented at the 2004-2008 International Liver Transplantation Society meetings. Liver Transpl 2014; 20: 355-360. [CrossRef]

10. Dossett LA, Fox EE, del Junco DJ, Zaydfudim V, Kauffmann R, Shelton J, et al. Don't forget the posters! Quality and content variables associated with accepted abstracts at a national trauma meeting. J Trauma Acute Care Surg 2012; 72: 1429-1434. [CrossRef]

11. Yalçınkaya M, Bagatur AE. Fate of abstracts presented at a National Turkish Orthopedics and Traumatology Congress: publication rates and consistency of abstracts compared with their subsequent full-text publications. Acta Orthop Traumatol Turc 2013; 47: 223-230. [CrossRef]

12. Donegan DJ, Kim TW, Lee GC. Publication Rates of Presentations at an Annual Meeting of the American Academy of Orthopaedic Surgeons. Clin Orthop Relat Res 2010; 468: 1428-1435. [CrossRef] 